STUDI

FRANCESI

\section{Studi Francesi}

Rivista quadrimestrale fondata da Franco Simone

142 (XLVIII | I) | 2004

Varia - fasc. I - gannio-aprile 2004

\title{
Victor Hugo 5; autour des Orientales, textes réunis et présentés par Claude Millet
}

\section{Judith Wulf}

\section{(2) OpenEdition}

1 Journals

\section{Édition électronique}

URL : https://journals.openedition.org/studifrancesi/40942

DOI : 10.4000/studifrancesi.40942

ISSN : 2421-5856

Éditeur

Rosenberg \& Sellier

\section{Édition imprimée}

Date de publication : 1 juillet 2004

Pagination : 210

ISSN : 0039-2944

\section{Référence électronique}

Judith Wulf, «Victor Hugo 5; autour des Orientales, textes réunis et présentés par Claude Millet », Studi Francesi [En ligne], 142 (XLVIII | I) | 2004, mis en ligne le 30 novembre 2015, consulté le 09 septembre 2021. URL : http://journals.openedition.org/studifrancesi/40942 ; DOI : https://doi.org/10.4000/ studifrancesi.40942

Ce document a été généré automatiquement le 9 septembre 2021.

\section{(c)}

Studi Francesi è distribuita con Licenza Creative Commons Attribuzione - Non commerciale - Non opere derivate 4.0 Internazionale. 


\title{
Victor Hugo 5; autour des Orientales, textes réunis et présentés par Claude Millet
}

\author{
Judith Wulf
}

\section{RÉFÉRENCE}

AA. VV., Victor Hugo 5; autour des Orientales, textes réunis et présentés par Claude MILLET, La Revue des lettres modernes, Paris-Caen, Minard, 2002, pp. 218

1 Comme le signale Claude MILLET dans son avant-propos, l'une des questions principales que pose le recueil des Orientales concerne la nature de l'Orient et la manière dont on peut le penser, comme altérité, mais aussi comme sujet d'une Histoire. Elle insiste notamment sur son statut de «fantasme d'Occidental» qui, au-delà de la question de la frontière géographique, pose le problème de la limite «d'une pensée politique des récents conflits et des nouveaux équilibres qui en résultent».

2 La question de l'altérité est d'abord abordée par Franck LAURENT («Orient / Occident: audelà du miroir», pp. 9-35) qui n'y voit ni pacifisme ni relativisme, mais la mise en cause d'un universalisme abstrait fondé sur la prééminence de l'Occident. Jean-Pierre VIDAL («L'épique dans Les Orientales», pp.37-58) s’intéresse au déplacement des frontières génériques qui s'opère dans le recueil. La notion d'épique, nécessitant de sortir de la logique du genre pour entrer dans celle de la catégorie générique, permet de compléter le travail sur le «transgénérique» initié par Les Odes et ballades. Ludmila CHARLES-WURTZ («Des Odes et Ballades aux Orientales - vers une libre circulation de la parole poétique», pp.59-78) poursuit l'étude du rapport entre les deux recueils en s'attardant plus précisément sur la question de l'énonciation: dans les Odes et Ballades, «le poète lyrique n'est plus, désormais, le détenteur exclusif de la parole poétique» le je lyrique se dilatant à une «infinité d'individualités» (p.67). Avec Les Orientales, la dimension politique intervient dans l'énonciation, le recueil intégrant «le régime de la parole 
qu'implique la révolution politique» (p. 78). La notion d'inspiration permet à Claude MILLET de dessiner le passage des Nouvelles Odes aux Orientales, le premier recueil préparant le renouvellement de cette conception, centrale dans le second («L'inspiration poétique - des Nouvelles Odes aux Orientales, pp.79-106). C'est la question de la limite entre poésie "extérieure» et poésie «intérieure» qui se pose ici, ainsi que celle des frontières entre le moi et Histoire, l'inspiration lyrique étant celle d'un «Je, dont la voix vibre de toutes les voix du monde et de l'Histoire». Sandrine RAFFIN s'interroge sur le paradoxe de l'accueil fait au recueil, composé d'hostilité et de critiques, même parmi les admirateurs de Hugo («Les Orientales - la réception critique en 1929, pp.107-138). Devenu emblématique de la révolution de la langue et de la société qui accompagne le romantisme, le recueil des Orientales «offre l'occasion d'en dénoncer les excès». La dimension politique, noyée dans les clivages politiques, est également négligée, l'accueil marquant aussi bien la nouveauté formelle que la «pensée poétique». Toujours dans une perspective de réception, Jean-Marc HOVASSE propose une étude de la lecture parnassienne des Orientales («Les Orientales et le Parnasse», pp.139-168). Analysant l'opposition entre la tentative satirique «d'acclimatation des Orientales» par Banville, qui connut un succès public puis un oubli rapide, et la poésie plus authentique et personnelle que Leconte de Lisle sut tirer de son analyse sur l'écart séparant le recueil des théories du Parnasse, il souligne combien Les Orientales "portent en germe l'avenir de la poésie, et tant celui de son auteur que celui du siècle» (p. 163).

Ces analyses sur Les Orientales sont complétées par une étude de Jean-Marc HovASSE intitulée «Verlaine et Hugo» (pp.171-218) qui souligne le rapport contradictoire unissant les deux poètes. Admirant l'homme, Verlaine est exaspéré par l'œuvre ou, plus précisément, se détourne de l'œuvre au moment où il se rapproche de l'homme (autour des Contemplations). 